\title{
Instituições e enforcement na redução do desmatamento na Amazônia
}

\author{
Daiana Brito dos Santos" \\ David Costa Correia Silva*** \\ Marcos Rodrigues ${ }^{* * * *}$
}

\section{Resumo}

Este artigo tem como objetivo avaliar o papel das instituições (formais e informais) em relação ao desmatamento na Amazônia, no período de 1988 a 2013. Em levantamento estatístico do desmatamento e dos autos de infração na região, foi possível estabelecer uma correlação com a evolução do ambiente legal institucional e verificar a atuação do Estado no cumprimento das leis ambientais (enforcement), avaliando mais especificamente os casos dos estados de Mato Grosso e Pará que são os estados com maior volume de desmatamento acumulado ao longo do período. Conclui-se que, embora a legislação e atuação do Estado tenham contribuído para a redução do desmatamento no período, a economia regional continua a se basear em atividades primárias extensivas (agricultura, pecuária e extrativismo vegetal e mineral) e que atividades ilegais continuam a existir, limitando a capacidade do ambiente formal institucional em conter o desmatamento.

Palavras-chave: Instituições. Legislação ambiental. Indústria madeireira. Agronegócio.

* Bacharel em Ciências Econômicas pela Universidade Estadual de Santa Cruz. Mestra em Planejamento do Desenvolvimento do Trópico Úmido pela Universidade Federal do Pará. E-mail: dai.dbrito@hotmail.com

** Bacharel em Ciências Econômicas. Mestre em Economia Regional pela Universidade Federal do Pará. Doutorando em Desenvolvimento Socioambiental no Programa de Pós-Graduação do Trópico Úmido pelo Núcleo de Altos Estudos Amazônicos da Universidade Federal do Pará. E-mail: davidcorreiasilva@hotmail.com

*** Bacharel em Administração pela Universidade Estadual do Mato Grosso. Doutorando em Desenvolvimento Socioambiental no Programa de Pós-Graduação do Trópico Úmido pelo Núcleo de Altos Estudos Amazônicos da Universidade Federal do Pará. E-mail: marcos.rodrigues.adm@gmail.com

http://dx.doi.org/10.5335/rtee.v22i47.6831

Submissão : 12/07/2016. Aceite: 21/09/2016. 


\section{Introdução}

Historicamente a inserção da Amazônia na instância econômica do mundo remete aos tempos da colonização do território brasileiro no século XVI, mas a região tornou-se de fato uma fronteira econômica para o Brasil a partir da década de 1970 com o Programa de Integração Nacional. As principais atividades desenvolvidas concentraram-se no setor primário, com extração vegetal, pecuária, agricultura e exploração de recursos minerais e energéticos, a maioria dessas atividades tem grande impacto no ambiente natural, causando a elevação das taxas de desmatamento (RIBEIRO, 2006).

Sobre o desmatamento verifica-se que houve incentivo do Estado brasileiro para a ocupação e desenvolvimento econômico da região e a crescente demanda mercadológica por recursos naturais proveniente da floresta, o que resultou em um contínuo processo de desmatamento para o progresso dessas atividades. Atualmente, a lógica de mercado de atendimento da demanda por meio do desflorestamento é visto como um problema e uma série de agentes governamentais e não governamentais tem se mobilizado para combater essa questão.

Sobretudo nas últimas décadas do século XX, o governo brasileiro criou mecanismos institucionais formais para regular a atividade madeireira por meio de uma legislação ambiental adequada à realidade que supõe o monitoramento das regiões estratégicas que disponham de recursos naturais de grande valia para agora ou no futuro, uma grande pressão por parte de governos e pessoas que valorizam a natureza e questionam o modelo de desenvolvimento implantado no mundo ao longo do tempo. Nesse sentido, o ambiente institucional no tratamento da natureza e recursos dela proveniente tem mudado e os governos têm um papel preponderante na organização de regras, isto é, fazer cumprir uma regulação que possa resguardar o interesse da coletividade.

Santos adiciona que: "em diversas regiões do mundo a cadeia produtiva da madeira representa objetos de investimentos e transações comerciais de elevado valor, isto é, representam um ativo de elevada liquidez, impactando no desenvolvimento dos países" (2015, p. 50). De acordo com Acevedo Marin e Araújo (2010) e Santos (2015), por diversas vezes a Amazônia desempenhou o papel da última grande fronteira aberta dos recursos naturais do mundo. Diante disso, pode-se inferir que a economia da madeira, representa a possibilidade de desenvolvimento regional de diversos municípios da Amazônia e, em alguns casos, pode representar até sua principal atividade econômica. 
Esse fato não é uma coincidência e nem cabe interpretações simplistas, de vê-lo como modismo do tema ou de contingência de pesquisa. A resposta é intrínseca à demanda do mercado florestal mundial, que apresenta $65 \%$ do suprimento mundial proveniente de florestas naturais; movimentando, desde 2005, a produção mundial de madeira na ordem de 3,5 bilhões de $\mathrm{m}^{3}$ /ano (FOOD AND AGRICULTURE ORGANIZATION, 2010).

Diante dessa situação, este artigo busca contribuir para a compreensão do papel das instituições formais sobre o desmatamento da Amazônia em anos recentes. O problema levantando questiona se o ambiente institucional é capaz de conter o desmatamento na Amazônia Legal. As instituições informais são originadas da tradição e da cultura de uma sociedade (FIANI, 2011; NORTH, 1994). Tal qual uma regra formal, as instituições formais também possuem papel no combate ao desmatamento. Embora seja complexo medir a pressão que surge das instituições informais, percebe-se que delas resultam a elaboração mais detalhada e ampliação do alcance da legislação, ou seja, instituições informais produzem um ambiente formal mais preciso e consistente com a necessidade de combate ao desmatamento.

A metodologia do trabalho procura discutir os impactos das regras formais na redução do desmatamento na Amazônia Legal, por meio da avaliação de parâmetros ambientais como taxa de desmatamento anual, autos de infração do Instituto Brasileiro do Meio Ambiente e do Instituto dos Recursos Naturais Renováveis (Ibama) e do mercado de trabalho, assim como as regras formais que limitam o desmatamento.

As regras formais impõem aos agentes econômicos a obediência por meio da lei, ou seja, o Estado tem o enforcement, o poder de execução legal e coercitivo para fazer as regras serem cumpridas. A Amazônia Legal é determinada pela Lei no 5.173, de 27 de outubro de 1966, e compreende os estados do Acre, Amapá, Amazonas, Mato Grosso, Pará, Roraima, Rondônia, Tocantins e parte do estado do Maranhão, região a oeste do meridiano 44․ O trabalho focaliza o desmatamento nos territórios mato-grossense e paraense em função deles acumularem as maiores taxas de desmatamento do país, motivo pelo qual as instituições formais tendem a serem executadas com maior intensidade em tais regiões.

\section{Instituições e enforcement}

Instituições são constrangimentos ou restrições criados para reduzir incertezas e conflitos bem como para aumentar as garantias e facilitar a cooperação dos agentes produtivos na coordenação das atividades econômicas. As instituições são 
compostas de regras formais, tais como constituições, leis, direitos de propriedade, ou informais, como costumes, tabus, tradições e códigos de conduta. North (1991, p. 91) afirma que historicamente as instituições foram criadas para por ordem e reduzir a incerteza nas trocas, determinar os custos de transação e de produção e, portanto, a rentabilidade e a viabilidade de se engajar na atividade econômica. $O$ estudo da evolução institucional é uma forma de se conectar o passado com o presente e o futuro, pois o desempenho de uma economia só pode ser entendido como parte de um processo sequencial histórico e são as instituições que fornecem a estrutura de incentivos de uma economia, elas moldam a direção da mudança econômica para o crescimento, estagnação ou declínio (NORTH, 1991).

$\mathrm{O}$ ambiente institucional em prol do desenvolvimento econômico deve facilitar a cooperação e reduzir a disputas, nesse sentido, vale destacar o termo enforcement, que designa a capacidade de execução de uma regra, sendo ela formal ou não (NORTH, 1991; NORTH, 1994; FIANI, 2011). Ou seja, é a capacidade de se constranger os agentes de maneira que determinadas decisões sejam cumpridas a favor do progresso coletivo.

Cabe ressaltar que o cumprimento de regras é um importante fator de desenvolvimento, pois a organização das atividades produtivas eficazes também depende das limitações impostas no ambiente institucional para inibir comportamentos oportunistas dos agentes. Naturalmente, os governos, entre as atribuições que lhes são investidas, detêm a capacidade de usar de coerção para o cumprimento das regras. Dessa maneira, os agentes devem saber que há fiscalização e sansões executadas pelo Estado aos desvios de conduta realizados pelos indivíduos que operam contra as normas vigentes.

Os Estados nacionais são constituídos por um aparato legal que serve para colocar ordem ao sistema social e econômico, nem que seja necessário impor sua autoridade, quer dizer, fazer cumprir a aplicação das leis ou regras de conduta formais (law enforcement), o que, na prática, significa defender os interesses da nação sobre os individuais (OLSON, 2002; XU; PISTOR, 2002).

Nas últimas décadas, os problemas ambientais são discutidos amplamente na sociedade mundial e em muitas ocasiões a sociedade brasileira foi provocada a responder pela questão do desflorestamento na Amazônia. O desmatamento na maior floresta tropical do planeta possui diversas justificativas econômicas e sociais. O Estado possui órgãos fiscalizadores e poderes para aplicação de punições que, se colocados em prática, gerariam o respeito às regras descritas nos códigos de conduta ambientais nacionais e, portanto, restringiria o desmatamento na Amazônia Legal. 


\section{Regulação ambiental no Brasil}

Mundialmente as questões ambientais ganharam importância na segunda metade do século XX, quando alguns eventos levaram à incorporação da dimensão ambiental à análise das políticas econômicas. Meadows, Randers e Meadows (2004) e Mueller (2007) destacam que a acentuação da poluição no primeiro mundo e a expansão industrial nos países de vanguarda industrial criavam um constante incremento na demanda por recursos naturais. A degradação das cidades, cujas regiões do entorno foram exposta pela poluição, os choques do petróleo da década de 1970 e o fim da energia a preços baixos e o relatório do Clube de Roma (Limits to Growth) demonstraria os limites físicos dos recursos naturais e do meio ambiente em assimilar a poluição e se regenerar. A partir de então ficava claro a importância estudar e tratar os problemas ambientais em âmbito global.

Na década de 1930, o Brasil já contava com ações governamentais a favor da preservação ambiental no país, o Código Florestal de 1934 (Decreto nº 23.793) obrigava os proprietários terras a manter $25 \%$ da área de seus imóveis com a cobertura de mata original. Dessa maneira, data de 1934, a elaboração do primeiro Código Florestal Brasileiro para regulamentar o uso da terra no sentido de preservar o meio natural.

Em 1965, outro Código Florestal foi instituído (Lei nº 4.771), levando-se em conta a modernização na cultura do solo, devido ao continuo avanço da agricultura, o Código Florestal de 1965 teve de se adequar às mudanças na lavoura e às novas perspectivas econômicas de crescimento da agricultura.

A partir de 1981, com a Lei da Política Nacional de Meio Ambiente (Lei $\mathrm{n}^{\mathrm{o}}$ 6.938), a estrutura da legislação ambiental começou a ser implantada no Brasil, abordando uma série de instrumentos (princípios e diretrizes) para a gestão ambiental e a fiscalização. Além disso, essa lei é considerada um marco no direito ambiental brasileiro, por ter criado o Sistema Nacional de Meio Ambiente (Sisnama). Na perspectiva de gestão ambiental do Sisnama, a capacidade de atuação do Estado na área ambiental baseia-se em responsabilidades compartilhadas entre União, Estados, Distrito Federal e municípios, além da relação desses com os diversos setores da sociedade.

A Figura 1 sistematiza como o Estado atua na gestão da política ambiental, de modo que o Sisnama surge para estabelecer um conjunto articulado de órgãos, entidades, regras e práticas em prol da proteção do meio ambiente, estruturando-se político-administrativamente por: a) Conselho de Governo, com assessoria direta ao presidente da República no que tange à formulação de diretrizes governamentais 
e a política nacional ambiental; b) Conselho Nacional do Meio Ambiente (Conama) é um órgão consultivo e deliberativo com a finalidade de assessorar o Conselho de Governo e propor diretrizes de políticas governamentais para o meio ambiente, e que engloba diferentes setores sociais: representantes de entidades de trabalhadores e da sociedade civil, representantes de entidades ambientalistas, representante de trabalhadores da área rural, representante de entidades profissionais com atuação na área ambiental e de saneamento indicado pela Associação Brasileira de Engenharia Sanitária e Ambiental, representante da comunidade indígena indicado pelo Conselho de Articulação dos Povos e Organizações Indígenas do Brasil e representantes dos ministérios públicos federal e estaduais; c) Ministério do Meio Ambiente (MMA), que funciona como órgão central, atua na formulação, no planejamento e na coordenação da política nacional e nas diretrizes governamentais para o meio ambiente; d) Instituto Brasileiro do Meio Ambiente e dos Recursos Naturais Renováveis, que atua como órgão executivo das políticas e diretrizes governamentais ambientais e sua fiscalização; e) os órgãos seccionais são entidades estaduais, como a Secretaria de Meio Ambiente (SEMA), direcionadas à execução de programas em prol do uso racional dos recursos naturais e projetos de controle e fiscalização das atividades potencialmente poluidoras.

Figura 1 - Atuação do Estado na gestão ambiental no Brasil

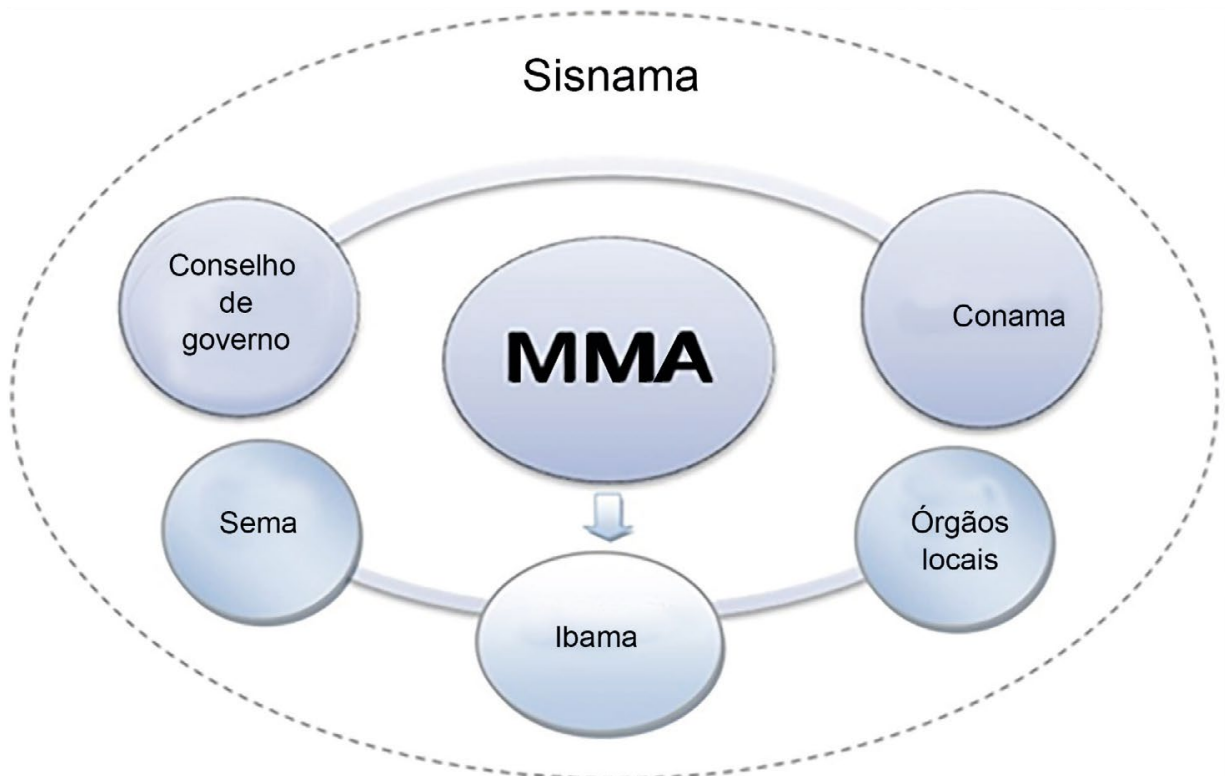

Fonte: elaboração dos autores com base na Lei da Política Nacional de Meio Ambiente (Lei nº 6.938/1981). 
Já os órgãos locais correspondem aos órgãos ou entidades municipais voltados ao meio ambiente, como as secretarias municipais, que são responsáveis por avaliar e estabelecer normas relativas ao controle e à manutenção da qualidade do meio ambiente, supletivamente ao Estado e à União.

É fundamental ressaltar que existem instrumentos jurídicos à disposição da sociedade para propor ação de responsabilidade por danos ao meio ambiente, como a Ação Civil Pública (Lei no 7.347/1985). A partir dessa lei, não apenas o particular, mas Ministério Público, autarquias, empresas públicas, fundações, sociedades de economia mista ou associações legalmente constituídas que apresentam em suas finalidades a proteção ao meio ambiente tornaram-se legalmente capazes de acionar os poluidores.

A Constituição federal (CF/1988) traz um capítulo específico sobre o meio ambiente (art. 255), ressaltando a importância de garantir a vida com qualidade para as gerações presentes e futuras. A orientação para proteção do meio ambiente aparece em vários artigos da $\mathrm{CF} / 1988$, inclusive obrigando que sejam feitos estudos de impacto ambiental para a instalação de obras ou atividades que possam causar danos ao meio ambiente. É importante observar que a partir de então, surge um novo arcabouço legal sobre meio ambiente nas esferas do governo brasileiro.

Assim, a legislação materializa a gestão ambiental pautada no principio da legalidade. A legislação ambiental surge para mudar comportamentos dentro de uma relação muitas vezes deletéria entre o homem e o meio ambiente. Ademais, dentro do que a sociedade busca enquanto desenvolvimento sustentável, a gestão ambiental pode ser interpretada como princípio, objetivo e instrumento. Entretanto, para se atingir o desenvolvimento sustentável dentro da perspectiva da educação ambiental deve-se respeitar alguns critérios, tais como, o uso social da propriedade. Inclusive, a esse respeito o art. $186 \mathrm{da} \mathrm{CF/1988} \mathrm{determina} \mathrm{que} \mathrm{uma} \mathrm{vez}$ que a propriedade rural atenda, simultaneamente, a critérios e graus de exigência estabelecida em lei, tais como aproveitamento racional, respeitando a utilização adequada dos recursos naturais disponíveis, preservando o meio ambiente e cumprir das disposições que regulam as relações de trabalho favorecendo o bem-estar dos proprietários e dos trabalhadores, tem-se o uso social da propriedade.

Dentro da ótica descentralizada da política e legislação ambiental no Brasil, a Lei Complementar $n^{\circ} 140$, de 8 de dezembro de 2011, define que constituem objetivos dos três entes da federação brasileira (União, Estados, Distrito Federal e municípios) a cooperação nas ações administrativas decorrentes do exercício da competência comum, relativas à proteção ao meio ambiente e combate à poluição e preservação da fauna e flora. 
A partir da criação da Lei de Crimes Ambientais (Lei nº 9.605/1998), tanto a pessoa física como a jurídica tornaram-se passíveis de sanções. Dito isso, percebe-se que a legislação ambiental brasileira é bastante avançada, é inclusive uma ferramenta pedagógica, dado que a Política de Educação Ambiental (Lei Federal $\mathrm{n}^{\circ}$ 9.795/1999) entende por educação ambiental os processos por meio dos quais o indivíduo e a coletividade constroem valores sociais, praticas e competências voltadas para a conservação do meio ambiente.

Em vigor a partir de julho de 2008, o Decreto oㅜ 6.514 estabelece as sanções administrativas a serem aplicadas em relação a crimes contra o meio ambiente. Esse decreto estabelece desde advertências e multas até a suspensão das atividades que infrinjam a legislação ambiental, passando a ser o principal meio legal para a aplicação da legislação ambiental e assegurar a preservação. O combate ao desmatamento ilegal, à exploração irregular de madeiras florestais, à comercialização de produtos da fauna e flora sem devida autorização, entre outros crimes, passam a ter a devida sanção, de um lado, coibindo-se a prática desses delitos devido à possibilidade da devida punição e, de outro, funciona como instrumento de ação dos poderes fiscalizados em caso de tais atividades.

\section{Desmatamento na Amazônia Legal}

A atividade madeireira é de suma importância no campo econômico, sendo responsável por impulsionar a economia de vários municípios amazônicos, uma vez que a exploração do recurso tende a aumentar a renda e o emprego das regiões nas quais essa atividade é realizada. Adicionalmente, a economia madeireira tende a abrir caminho para atividades como a pecuária e agricultura (FERREIRA; VENTICINQUE; ALMEIDA, 2005). Ainda nessa perspectiva, a exploração de madeira insere-se no setor da indústria de transformação, uma área econômica importante, pois agrega valor ao produto e ainda irradia efeitos no desempenho de outros setores, como o de comércio e serviços.

Em que pese à dinâmica econômica que a extração de madeira promove, o desflorestamento é um dos principais problemas ambientais existentes na Amazônia. O Gráfico 1 demonstra a evolução das taxas de desmatamento $\left(\mathrm{km}^{2} / \mathrm{ano}\right)$ para os estados do Pará, Mato Grosso e os demais estados da Amazônia Legal, no período entre 1988 e 2013. 
Gráfico 1 - Taxa de desmatamento nos estados da Amazônia, de 1988 a 2013, (km²/ano) ${ }^{1}$

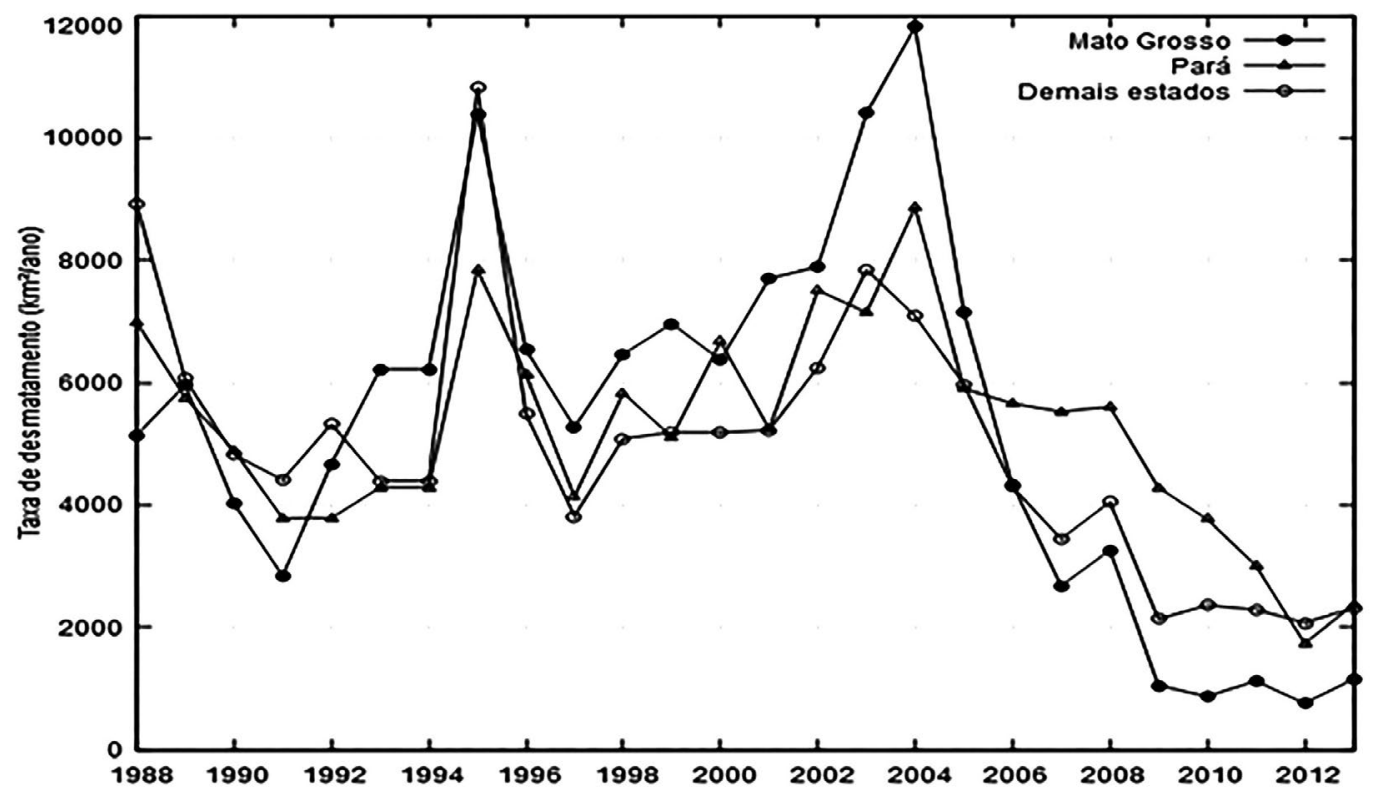

Fonte: elaboração dos autores com base em Instituto Nacional de Pesquisas Espaciais (2013).

Verifica-se que o desmatamento acumulado entre 1988 a 2013 é superior a $400 \mathrm{mil} \mathrm{km}^{2}$, as taxas de desmatamento na Amazônia Legal nos últimos períodos são inferiores as das primeiras observações e as unidades federativas que acumulam a maior quantidade de desmatamento são o Mato Grosso $\left(137.251 \mathrm{~km}^{2}\right)$ e o Pará (136.127 km²). Vale destacar que desde 2006 o desmatamento no território paraense é o maior da Amazônia Legal (INSTITUTO NACIONAL DE PESQUISAS ESPACIAIS, 2013).

As causas e incentivos ao desmatamento são diversificados e tendem a variar ao longo do tempo, alguns autores apontam o incentivo à colonização regional, à construção de estradas, ao acesso a crédito, às dinâmicas econômicas do setor agropecuário, entres outras razões, em muitas ocasiões com auxílio estatal. Porém, nos últimos anos, o Estado usa sua influência (enforcement) para reduzir as taxas de desflorestamento e isso tem tido impacto na extração de madeira legal. A Tabela 1 apresenta dados de empresas e empregos formais no Mato Grosso, Pará e demais estados da Amazônia Legal no período de 2002 a 2013. 
Tabela 1 - Total de empregos formais e empresas ativas no setor madeireiro nos estados da Amazônia no período de 2002 a 2013

\begin{tabular}{l|r|r|r|r|r|r}
\hline \multirow{2}{*}{ Ano } & \multicolumn{2}{|c|}{ Mato Grosso } & \multicolumn{2}{c|}{ Pará } & \multicolumn{2}{c}{$\begin{array}{c}\text { Demais estados da } \\
\text { Amazônia Legal }\end{array}$} \\
\cline { 2 - 7 } & Empregos & Empresas & Empregos & Empresas & Empregos & Empresas \\
\hline 2002 & 22.580 & 1.659 & 34.586 & 1.151 & 19.551 & 1.244 \\
2003 & 22.707 & 1.664 & 36.486 & 1.235 & 18.906 & 1.278 \\
2004 & 24.562 & 1.684 & 41.566 & 1.268 & 20.935 & 1.352 \\
2005 & 17.812 & 1.650 & 36.565 & 1.240 & 19.319 & 1.388 \\
2006 & 18.779 & 1.567 & 37.495 & 1.205 & 17.100 & 1.348 \\
2007 & 18.974 & 1.558 & 33.933 & 1.200 & 18.270 & 1.407 \\
2008 & 17.933 & 1.621 & 25.595 & 1.129 & 16.517 & 1.375 \\
2009 & 17.111 & 1.628 & 23.172 & 1.053 & 15.345 & 1.367 \\
2010 & 17.055 & 1.602 & 25.690 & 1.045 & 16.588 & 1.391 \\
2011 & 16.816 & 1.629 & 25.211 & 1.084 & 16.326 & 1.374 \\
2012 & 16.559 & 1.634 & 22.587 & 1.113 & 15.607 & 1.388 \\
2013 & 15.911 & 1.595 & 19.845 & 1.105 & 15.597 & 1.437 \\
\hline
\end{tabular}

Fonte: Brasil (2014b).

Os dados da Tabela 1 mostram que em todas as regiões estudadas tanto o número de empresas (esse em menor proporção) quanto o de empregos formais no setor madeireiro está declinando, acompanhando a queda do desmatamento, mas também impactando a economia da região devido à própria redução do emprego. No que tange à fiscalização ambiental do setor florestal, a Tabela 2 apresenta a quantidade de autos de infração ${ }^{2}$ de flora lavrados pelo Ibama, correspondentes aos estados do Pará, Mato Grosso e demais estados da Amazônia Legal no período entre 2008 e 2012 . 
Tabela 2 - Número de autos de infração de flora aplicados pelo Ibama entre 2008 e 2012

\begin{tabular}{l|r|r|r}
\hline \multicolumn{1}{c|}{ Ano } & Mato Grosso & Pará & $\begin{array}{c}\text { Demais estados da } \\
\text { Amazônia Legal }\end{array}$ \\
\hline 2008 & 1.614 & 2.056 & 4.053 \\
2009 & 1.383 & 1.548 & 3.242 \\
2010 & 863 & 1.486 & 3.100 \\
2011 & 1.261 & 1.412 & 2.407 \\
2012 & 1.066 & 1.177 & 1.860 \\
Total & 6.187 & 7.679 & 14.662 \\
\hline
\end{tabular}

Fonte: elaboração dos autores com base em Ibama (2013).

De maneira similar às taxas de desmatamento, os estados do Pará e Mato Grosso são as regiões em que o Ibama mais registra autos de infrações de flora. Como mostra a Tabela 2, na área de estudo foram lavrados 28.528 autos de infração, desses, $49 \%$, ou seja 13.866 registros, foram nos dois principais estados desmatadores. Verifica-se também que há uma tendência de queda nas quantidades multas, isso é relevante, pois a atuação do Ibama representa um tipo de law enforcement, já que o Estado age punindo eventuais infratores. Entretanto, com a tendência de queda nessas punições, há também disposição de queda nas taxas de desmatamento, o que podemos abstrair como uma mudança de comportamento dos agentes em curso no setor florestal. Na próxima seção analisaremos mais detalhadamente os impactos da legislação e os resultados no Mato Grosso e Pará.

\section{Análise do caso no Mato Grosso}

O estado de Mato Grosso faz parte da Amazônia Legal e, junto com o Pará, é um dos estados da Amazônia que apresentou maiores índices de desmatamento nos últimos anos (conforme o Gráfico 1). A exploração econômica de base primária (principalmente a pecuária, agricultura e indústria madeireira) é a principal causa para esses elevados índices de desmatamento.

Em relação ao ambiente institucional legal, o Código Ambiental Estadual de Mato Grosso surge em 1995 como uma primeira forma de intervenção sobre o desmatamento no estado, pois estabelece instrumentos de licenciamento e estudos de impactos ambientais de atividades que possam causar dano ao meio ambiente, ai 
incluído o desmatamento. Essa é uma das primeiras formas do governo em nível estadual (enforcement) de atuar sobre a questão ambiental.

A vocação da região como fronteira agrícola teve início com o Plano de Integração Nacional, durante as décadas de 1960 e 1970, que visava o aproveitamento econômico da região e desenvolvimento de atividades produtivas. A abundância de recurso madeireiro na floresta Amazônica permitiu o rápido desenvolvimento dessa atividade na região. Marta (2007) afirma que a extração permitia a internalização de recursos e contribuía (por meio da derrubada e queima) para atividades que seriam implantadas posteriormente, como a agricultura e a pecuária. A atividade pecuária permitia a concentração fundiária, característica da região por ser uma forma de ocupar grandes áreas de terra e realizar uma atividade nela que exigia pouco capital.

A partir, principalmente da década de 1990, a soja ganhou espaço considerável no cenário mato-grossense, sendo o principal produto de exportação do estado, com mais de 12,3 milhões de toneladas exportadas em 2013 (BRASIL, 2014a). Partindo das áreas de cerrado e indo em direção à Amazônia, a soja se expandiu a partir da ocupação de áreas de floresta nativa (provocando o desmatamento) ou a partir da substituição da pecuária por esta cultura (nesse caso, as áreas já estavam desmatadas).

Analisando o papel das instituições em Mato Grosso, pode-se dividi-lo em dois momentos: o primeiro, representa a expansão das atividades econômicas dentro do estado, que compreende o período de colonização promovido durante o Plano de Integração Nacional até aproximadamente 2004. Nesse período, embora existam regulações formais quanto ao problema do desmatamento, o mercado foi o principal agente regulador, quando a lógica de oferta e demanda atuou no sentido da expansão das atividades, promovendo tanto o crescimento econômico como também o desmatamento por meio da extensão da produção. O mercado pode ser caracterizado como uma instituição informal, na qual os agentes orientam-se pela lei de oferta e procura. $\mathrm{O}$ aumento da demanda por produtos primários incentivou a expansão das atividades. Imori et al (2011), ao realizar estudo sobre a emissão de gases de efeito estufa na região Amazônica, perceberam que o desmatamento é o principal meio emissor desses gases e que ocorre devido à expansão das atividades agropecuárias (principalmente gado, soja, cana-de-açúcar), mas tais atividades são o principal meio de desenvolvimento econômico da região e grande parte da pressão para expansão das atividades ocorre pela demanda externa dos produtos.

A soja passou de uma demanda no mundo aproximada de 47 milhões de toneladas em 1972 para 241 milhões de toneladas em 2012, um incremento de mais de 
400\% (FOOD AND AGRICULTURE ORGANIZATION, 2012). O rebanho bovino do Mato Grosso em 1974 era de 11 milhões de cabeças, aumentou para 28 milhões de cabeças em 2012, e o estado passou a concentrar o maior rebanho bovino do país (INSTITUTO BRASILEIRO DE GEOGRAFIA E ESTATÍSTICA, 2012).

O segundo momento é caracterizado por uma crise dentro da instituição informal, que é o mercado, e pela ascensão de instituições formais, com objetivos claros de reduzir o nível de desmatamento, principalmente, daquele provocado pela expansão das atividades primárias na Amazônia. A partir de 2004, o preço da soja caiu drasticamente de uma média nacional de $\mathrm{R} \$ 51,11 /$ saca, em março de 2004, para $R \$ 28,17 /$ saca, em novembro de 2005 (CENTRO DE ESTUDOS AVANÇADOS EM ECONOMIA APLICADA, 2004; CENTRO DE ESTUDOS AVANÇADOS EM ECONOMIA APLICADA, 2005), ou seja, o mercado (como instituição informal) por meio da mesma concepção de oferta e demanda que orientou a expansão inicial dessa atividade, agora atua como limitador de expansão da soja na Amazônia. Já a partir de 2005 é possível notar uma queda da taxa de desmatamento, de $11.814 \mathrm{~km}^{2}$, em 2004, para $7.145 \mathrm{~km}^{2}$, em 2005 (INSTITUTO NACIONAL DE PESQUISAS ESPACIAIS, 2013).

A moratória da soja, a partir de 24 de julho de 2006, é um acordo firmado entre as empresas de comercialização de soja para que não comprem mais o produto quando originário de áreas desflorestadas na Amazônia (RUDORF et al., 2011). Essa proposta surge como uma instituição formal, organizada pelos próprios agentes privados frente à questão ambiental que toma conta no mundo e produz impactos diretos sobre o desmatamento na Amazônia devido à expansão da soja. A impossibilidade de comercialização do produto atua como restrição aos proprietários de terra dentro da Amazônia, forçando a expansão dessa atividade continuamente para áreas de cerrado (CAMPOS, 2012).

Outra instituição formal é o Decreto oㅜ 6.514 , de 2008, que passou a ser instrumento para punir infrações contra o meio ambiente, na qual está incluído o desmatamento ilegal dentro da Amazônia, principalmente, por expansão das atividades primárias, como a madeireira, a pecuária e, parcialmente, a própria soja. Nesse mesmo ano intensifica-se o monitoramento de desmatamento ilegal na Amazônia (como as operações Arco de Fogo da Polícia Federal e Guardiões da Amazônia do Ibama), atuando tanto em relação a ações preventivas contra o desmatamento como também realizando diversas apreensões tanto de madeira ilegal e como efetuando prisões, reduzindo a extração ilegal na Amazônia. 


\section{Análise do caso no Pará}

Desde 2006, o estado do Pará é o principal desflorestador do país, contudo, a partir de 2008, excetuando-se o último período, inseriu-se uma tendência de queda nas taxas de desmatamento no território paraense (Gráfico1). O desmatamento nos primeiros anos do século XXI tem sido influenciado pelas atividades agropecuárias. Apesar de ter assumido a primeira posição na geração do desmatamento no Brasil, cabe ressaltar que existem esforços institucionais nacionais e regionais no sentido de reduzir a taxa de desmatamento, assim vale destacar a legislação ambiental do Estado do Pará está em consonância com a legislação federal.

Ao longo dos anos extração madeireira na Amazônia foi responsável por dinamizar a economia de muitas regiões paraenses, a inserção dessa atividade propiciou o desenvolvimento de práticas agropecuárias, em especial para produção bovina. A criação de gado nas áreas desmatadas consolidou no Pará mais um ciclo produtivo no estado (MONTEIRO, 2005). Sobre as principais causas de desmatamento na Amazônia Legal, Rivero et al. (2009) apontam que uma forte correlação entre pecuária e desflorestamento, a soja também aparece positivamente correlacionada com o desmatamento.

Com a tendência de crescimento da demanda nacional e internacional por commodities agropecuárias o Estado brasileiro tende a lançar mão do law enforcement para regular as atividades madeireiras e limitar a devastação das florestas nativas, visto que o mercado tende a demorar demasiadamente para controlar os problemas ambientais, tendo em vista que uma parte significativa da extração de madeira é ilegal, devido ao descumprimento da legislação ou à exploração em áreas proibidas, a ação governamental é fundamental. Segundo Pereira et al. (2010), em 2009, foram extraídos 14,1 milhões de metros cúbicos de madeira em tora na Amazônia, desse montante, $64 \%$ (ou 9,4 milhões de metros cúbicos) foram autorizados legalmente para exploração, no Pará a proporção de madeira autorizada para extração foi de $38 \%$.

O combate à ilegalidade é realizado com ações de controle pelos órgãos de repressão estatais que conta com ações perpetradas pelas entidades de cunho ambiental com o apoio da polícia e exército. Como foi mostrado, o Estado brasileiro está operando para criar um ambiente institucional capaz de reduzir a extração de madeira, em especial a extração ilegal. No Pará, há alguns avanços, mas ainda há pontos relevantes a serem tratados no que se diz respeito à fiscalização e ao controle. 


\section{Considerações finais}

Embora o desmatamento continue a existir na Amazônia, foi possível perceber uma redução nos índices ao longo das últimas duas décadas. Ações do Estado contribuíram para essa redução, como a atividade legislativa representando o papel de regulação (ambiente formal) e a fiscalização representando a execução dessas normas (enforcement). Todavia, atividades ilegais continuam a ocorrer em todos os setores, daí cabe aos órgãos fiscalizadores fazerem valer as normas formais já existentes por meio de sua devida aplicação.

Entretanto, aparentemente as reformas nas estruturas do Ibama e do Ministério do Meio Ambiente ainda não expressam instrumentos pertinentes que viabilizem um projeto de desenvolvimento sustentável para o setor madeireiro, dado o crescente número de multas aplicadas contra crimes de flora.

Instituições informais podem tanto contribuir para o aumento como para a redução do desmatamento. A ocupação da Amazônia a partir das décadas de 1950 e 1960 foi baseada no modelo capitalista agroextrativista e persiste até hoje. De um lado, esse modelo foi expansivo, fomentando a produção econômica a partir da substituição da floresta nativa da Amazônia, permitindo o crescimento da região; de outro, foi incentivado e retraído por instrumentos de mercado, como o preço regulando a oferta e demanda e acordos (como o embargo da soja) entre empresas, sociedade civil e o Estado para conter o avanço da produção agrícola sobre a região.

Esse conjunto de situações aponta que as instituições conseguiram reduzir o desmatamento (quando voltadas para esse fim), embora não o tenham eliminado completamente, a atividade econômica da região continua a ser baseado na exploração agroextrativista, o que fomenta tanto sua expansão pela necessidade de crescimento econômico como também atividades ilegais ligadas a esse setor.

Nesse sentido, explorar estratégias de desenvolvimento regional, como o incentivo a atividades de menor impacto, cooperação entre agentes, fortalecimento de setores sustentáveis e geradores de mão de obra, é uma forma de contribuir com a sustentabilidade além de serem capazes de ampliar a geração de renda e fortalecer o crescimento econômico (COSTA, 2012; TAVARES, 2011). Sugere-se que trabalhos futuros possam demonstrar como iniciativas locais, que se baseiam em instituições informais, conseguem contribuir para o desenvolvimento e preservação do meio ambiente. 


\title{
Institutions and enforcement to reduce the deforestation in Amazon
}

\begin{abstract}
This article aimed to evaluate the role of institutions (formal and informal) on deforestation in the Amazon from 1988 to 2013. Through statistical survey of deforestation and tax assessments in the region, it was possible to establish a correlation with the evolution of the institutional and legal environment verify the performance of the State in compliance with the environmental laws (enforcement), specifically evaluating the cases of Mato Grosso and Pará that are the states with the highest volume of accumulated deforestation during period. Was possible to conclude that, although the legislation and state action have contributed to reducing deforestation in the period, the regional economy continues to be based on extensive primary activities (agriculture, livestock and vegetable and mineral extraction) as well illegal activities still exist, limiting the ability of the formal institutional environment to contain the deforestation.
\end{abstract}

Keywords: Institutions. Environmental legislation. Timber industry. Agribusiness.

\section{Instituciones y enforcement en la reducción de la deforestación en la Amazonia}

\section{Resumen}

Este estudio tuvo como objetivo evaluar el papel de las instituciones (formales e informales) sobre la deforestación en la Amazonía entre los años 1988-2013. A través de estudios estadísticos de las evaluaciones de la deforestación y los fiscales en la región, fue posible establecer una correlación con la evolución del entorno jurídico institucional y comprobar el estado de las operaciones en el cumplimiento de la ley (ejecución), evaluar de manera más específica los casos de los estados de Mato Grosso y Pará que son los estados con el mayor volumen de la deforestación acumulada durante el período. Se concluye que, si bien la legislación y la acción del estado han contribuido a la reducción de la deforestación en el período, la economía regional sigue basándose en las actividades primarias extensas (agricultura, ganadería y vegetales y extracción de minerales) y las actividades ilegales todavía existen, lo que limita la capacidad del medio ambiente institucional formal en la contención de la deforestación.

Palabras clave: Instituciones. Legislación ambiental. Industria de la madera. La agroindustria. 


\section{Notas}

1 Segundo dados divulgados pelo Instituto Nacional de Pesquisas Espaciais, o resultado de 1988 é a média entre os anos de 1977 e 1988, os resultado de 1993 e 1994 são médias entre esses anos e os dados de 2013 são provenientes de estimação.

2 Os autos de infração referem-se a multas aplicadas pelo Ibama a pessoas físicas ou jurídicas que tenham cometido alguma ação indevida sobre flora.

\section{Referências}

ACEVEDO MARIN, Rosa Elizabeth; TAPAJÓS ARAÚJO, Marlon Aurélio. Território tradicional e fronteira na Amazônia: conflito entre as comunidades tradicionais de Juruti Velho e a empresa mineradora Alcoa. In: CONGRESSO LATINO-AMERICANO DE SOCIOLOGIA RURAL, 8, 2010. Anais... Porto de Galinhas, 2010.

BRASIL. Balança comercial: unidades da federação - janeiro a dezembro 2013. 2014a. Disponível em: <http://www.mdic.gov.br/sitio/interna/interna.php?area=5\&menu=4505\&refr=1076>. Acesso em: 29 ago. 2014.

. Constituição (1988). Constituição da República Federativa do Brasil. Diário Oficial [da] República Federativa do Brasil, Poder Executivo, Brasília, DF, 5 out. 1988. Seção 1, p. 1.

Decreto $n^{\circ}$ 6.514, de 22 de julho de 2008. Dispõe sobre as infrações e sanções administrativas ao meio ambiente, estabelece o processo administrativo federal para apuração dessas infrações, e dá outras providências. Diário Oficial [da] República Federativa do Brasil, Poder Executivo, Brasília, DF, 23 jul. 2008. Seção 1, p. 1.

Decreto no 23.793, de 23 de janeiro de 1934. Aprova o Código Florestal que com este baixa. Diário Oficial [da] República Federativa do Brasil, Poder Executivo, Brasília, DF, 9 fev. 1934. Seção 1, p. 2.882.

Lei no 4.771, de 15 de setembro de 1965. Institui o novo Código Florestal. Diário Oficial [da] República Federativa do Brasil, Poder Executivo, Brasília, DF, 16nov. 1965. Seção 1, p. 9.529.

Lei $\mathrm{n}^{\circ} 5.173$, de 27 de outubro de 1966. Dispõe sobre o Plano de Valorização Econômica da Amazônia; extingue a Superintendência do Plano de Valorização Econômica da Amazônia, cria a Superintendência do Desenvolvimento da Amazônia , e dá outras providências. Diário Oficial [da] República Federativa do Brasil, Poder Executivo, Brasília, DF, 31 out. 1966. Seção 1, p. 12.563.

. Lei $\mathrm{n}^{\circ}$ 6.938, de 31 de agosto de 1981. Dispõe sobre a Política Nacional do Meio Ambiente, seus fins e mecanismos de formulação e aplicação, e dá outras providências. Diário Oficial [da] República Federativa do Brasil, Poder Executivo, Brasília, DF, 2 set. 1981. Seção 1, p. 16.509.

Lei $\mathrm{n}^{\circ}$ 7.347, de 24 de junho de 1985. Disciplina a ação civil pública de responsabilidade por danos causados ao meio ambiente, ao consumidor, a bens e direitos de valor artístico, estético, histórico, turístico e paisagístico (VETADO) e dá outras providências. Diário Oficial [da] República Federativa do Brasil, Poder Executivo, Brasília, DF, 25 jul. 1985. Seção 1, p. 10.649.

Lei $\mathrm{n}^{\circ} 9.605$, de 12 de fevereiro de 1998. Dispõe sobre as sanções penais e administrativas derivadas de condutas e atividades lesivas ao meio ambiente, e dá outras providências. 
Diário Oficial [da] República Federativa do Brasil, Poder Executivo, Brasília, DF, 13 fev. 1998. Seção 1, p. 1.

Lei no 9.795, de 27 de abril de 1999. Dispõe sobre a educação ambiental, institui a Política Nacional de Educação Ambiental e dá outras providências. Diário Oficial [da] República Federativa do Brasil, Poder Executivo, Brasília, DF, 28 abr. 1999. Seção 1, p. 1.

Lei Complementar no 140, de 8 de dezembro de 2011. Fixa normas, nos termos dos incisos III, VI e VII do caput e do parágrafo único do art. 23 da Constituição federal, para a cooperação entre a União, os Estados, o Distrito Federal e os municípios nas ações administrativas decorrentes do exercício da competência comum relativas à proteção das paisagens naturais notáveis, à proteção do meio ambiente, ao combate à poluição em qualquer de suas formas e à preservação das florestas, da fauna e da flora; e altera a Lei no 6.938, de 31 de agosto de 1981. Diário Oficial [da] República Federativa do Brasil, Poder Executivo, Brasília, DF, 9 dez. 2011. Seção 1, p. 1.

. Ministério do Trabalho e Emprego. Relatório Anual de Informações Sociais. 2014b. Disponível em: <http://bi.mte.gov.br/>. Acesso em: 2 set. 2014.

CAMPOS, Índio. Limites e condicionantes à expansão da sojicultura na Amazônia. Novos Cadernos NAEA, Belém, v. 15, n. 2, p. 197-216, 2012.

CENTRO DE ESTUDOS AVANÇADOS EM ECONOMIA APLICADA. Departamento de Economia, Administração e Sociologia da Escola Superior de Agronomia Luiz de Queiroz. Universidade de São Paulo. Soja. 2004. Disponível em: <http://www.cepea.esalq.usp.br/agromensal/2004/03_ marco/Soja.htm>. Acesso em: 12 de ago. 2014.

. Soja. 2005. Disponível em: <http://www.cepea.esalq.usp.br/agromensal/2005/11_novembro/Soja.htm>. Acesso em: 12 de ago. 2014.

COSTA, Francisco de Assis. Formação rural extrativista na Amazônia: os desafios do desenvolvimento capitalista (1720-1970). Belém: NAEA, 2012.

FIANI, Ronaldo. Cooperação e conflito: instituições e desenvolvimento econômico. Rio de Janeiro: Campus-Elsevier, 2011.

FERREIRA, Leandro Valle; VENTICINQUE, Eduardo; ALMEIDA, Samuel. O desmatamento na Amazônia e a importância das áreas protegidas. Estudos Avançados, São Paulo, v. 19, n. 53, p. 157-166, 2005.

FOOD AND AGRICULTURE ORGANIZATION. United Nations. Food and agricultural commodities production. 2012. Disponível em: <http://faostat.fao.org/site/339/default.aspx >. Acesso em: 12 ago. 2014.

Global Forest Resources Assessment 2010, Rome, 2010.

IMORI, D. et al. Regional development and greenhouse gases emission: the case of the Amazon region. In: ENCONTRO NACIONAL DE ECONOMIA, 39. Anais..., Foz do Iguaçu, 2011.

INSTITUTO BRASILEIRO DE GEOGRAFIA E ESTATÍSTICA. Pesquisa pecuária municipal. 2012. Disponível em: <http://www.sidra.ibge.gov.br/bda/tabela/protabl.asp?c=73\&z=t\&o=24\&i=P>. Acesso em: 12 ago. 2014.

INSTITUTO BRASILEIRO DO MEIO AMBIENTE E DOS RECURSOS NATURAIS RENOVÁVEIS. Sistema de Cadastro, Arrecadação e Fiscalização. Autos de infrações de flora. Brasília, 2013. 1 CD-ROM. 
INSTITUTO NACIONAL DE PESQUISAS ESPACIAIS. Taxas anuais de desmatamento - 1998 até 2013. 2013. Disponível em: <http://www.obt.inpe.br/prodes/prodes_1988_2013.htm>. Acesso em: 11 ago. 2014.

MARTA, José Manuel. Desenvolvimento territorial e ruralidade. In: CONGRESSO DA SOCIEDADE BRASILEIRA DE ECONOMIA, ADMINISTRAÇÃO E SOCIOLOGIA RURAL, 45. Anais... Londrina, 2007.

MEADOWS, Donella; RANDERS, Jorgen; MEADOWS, Dennis. Limits to growth: the 30 year update. White River Junction: Chelsea Green, 2004.

MONTEIRO, Maurílio de Abreu. Meio século de mineração industrial na Amazônia e suas implicações para o desenvolvimento regional. Estudos avançados, São Paulo, v. 19, n. 53, p. 187-207, 2005.

MUELLER, Charles C. Os economistas e as relações entre o sistema econômico e o meio ambiente. Brasília: UNB, 2007.

NORTH, Douglass C. Institutions. Journal of Economic Perspectives, Pittsburgh, PA, v. 5, n. 1, p. 97-112, 1991.

. Economic performance through time. The American Economic Review, Pittsburgh, PA, v. 84, n. 3, p. 359-368, 1994.

OLSON, M. The logic of collective action: public goods and the Theory of Groups. Cambridge, MA: Havard University, 2002.

PEREIRA, D. et al. Fatos florestais da Amazônia 2010. Belém: IMAZON, 2010.

RIBEIRO, N. de F. A questão geopolítica da Amazônia: da soberania difusa à soberania restrita. Belém: Edufpa, 2006.

RIVERO, Sérgio et al. Pecuária e desmatamento: uma análise das principais causas diretas do desmatamento na Amazônia. Nova Economia, Belo Horizonte, v. 19, n. 1, p. 41-66, 2009.

RIVERO, S.; ROSÁRIO, L.; ALMEIDA, O. Instituições, gestão dos recursos naturais e o setor madeireiro no estado do Pará. Amazônia: Ciência \& Desenvolvimento, Belém, v. 7, n. 13, jul./dez. 2011.

RUDORF, Bernardo Friedrich Theodor et al. The soy moratorium in the Amazon biome monitored by remote sensing images. Remote Sensing, Basel, v. 3, n. 1, p. 185-202, 2011.

SANTOS, Daiana Brito dos. Economia madeireira: dificuldades de regulação e efeito sobre quilombolas no Arquipélago do Marajó. Dissertação (Mestrado Multidisciplinar em Planejamento do Desenvolvimento) - Universidade Federal do Pará, Belém, 2015.

TAVARES, Hermes Magalhães. Estratégias de desenvolvimento regional. Da grande indústria ao arranjo produtivo local? Revista Brasileira de Gestão e Desenvolvimento Regional, Taubaté, v. 7, p. 50-68, 2011.

XU, C.; PISTOR, K. Law enforcement under incomplete law: theory and evidence from financial market regulation. London: School of Economics, 2002. Working paper no ${ }^{\circ}$ TE/02/442. 